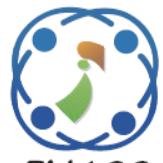

\title{
Unified Particle Swarm Optimization Based Distributed Generation Placement in Radial Power Systems
}

\author{
Dhanavijayan Ramakrishnan $^{1 *}$ Sudhakar Pushparajan ${ }^{2}$ \\ ${ }^{I}$ Prist University, Thanjavur, India \\ ${ }^{2}$ Annamalai University, Chidambaram, India \\ * Corresponding author’s Email: rdhanavijayan@gmail.com
}

\begin{abstract}
This paper demonstrates an ideal procedure to find the desirable bus location and operating power of distributed generation in radial power distribution system with the aid of unified particle swarm optimization algorithm. In general, an electrical power network economics primarily relies on the conductor line losses. Hence in the proposed study, the network active power loss is picked as the minimization problem, and it is reduced by incorporating optimum distributed energy source at appropriate buses using proposed unified particle swarm optimization algorithm. The system power loss is handled as the cost function for each particle in a swarm. The simulation analysis of the purposed procedure is successfully executed for different radial distribution system using MATLAB. The prosperous solutions achieved from the simulation studies manifest that the high level of system loss reduction and desirable bus voltage profile, when compared against earlier existing methods such as genetic algorithm, particle swarm optimization, and parameter improved particle swarm optimization.
\end{abstract}

Keywords: Distributed generation, Particle swarm optimization, Radial distribution system, Real power loss, Unified particle swarm optimization.

\section{Introduction}

The power generated from the power station is dispersed to the various load consumers through transmission and distribution systems. It is substantially notable that the electrical power produced at the generating stations not levels with the load devoured by the customers, because of the small extent of energy loss occurred while the electrical power is sent to end customers. The most extreme rate of energy loss in an electric grid is due to transmission and distribution line losses. The apparent power loss of an AC transmission and distribution line is expressed in complex form $I^{2}$ $(R+j X)$. On account of substantial resistance $(\mathrm{R})$ to reactance $(\mathrm{X})$ ratio characteristics of the radial distribution system (RDS) [1], the primary component of the apparent power loss in an AC distribution line is real power loss. Since the resistance is a real portion of $\mathrm{AC}$ distribution line impedance, the resistive loss in an AC system equivalent to active power loss. The power line resistive loss reduction in an AC distribution system presumes an essential part in economic operation and planning of a complete power system. Thus the objective of the presented study is to reduce the real power loss of RDS. Distributed generation (DG) integration in RDS is experiencing rapid growth in lots of nations due to its availableness of various power sources like photovoltaic cells, fuel cells and wind energy conversation systems. DG is commonly integrated with a de-centralized fashion by the idea of micro-grid. A droop based advanced powersharing controller method for shunt connected voltage source inverters have been developed, and the proposed approach has an advantage of eliminating the data communication among the DGs $[2,3]$.

Typically, the loss minimization problem in an electrical power network is very critical and most difficult tasks to solve. In this proposed study, active power supporting DG installed at suitable bus can 
reduce the power loss of the $\mathrm{AC}$ distribution network. Because the active power loss of an electrical system is directly proportional to the real part of the line current, an energy source producing active power can reduce the system loss. Thus, a DG producing active power (power generating station equipped with the solar cell or hydrogen fuel cell) installed at situation node of a distribution system can reduce the active power loss by minimizing the current withdrawn from the sub-station [4,5]. Present days, the idea of integrating the active power delivering DGs in RDS has been increased in greater extent due to its smooth implementation and enhanced network performances [6-9]. In light of the various favorable circumstances of DG incorporated system, the optimum rating and placing of DGs in a distribution system with the aid of naturally propelled artificial algorithms turn out to be more energizing and popular vogues in the domain of radial distribution network optimization and enhancement. The optimum sizing and placing of DGs in distribution network has been developed with the application of genetic algorithm (GA) [6, 7]. The GA based optimal DG placement in RDS has lots of superior advantage over the conventional methods, and it takes care of most essential problem limitations such as node voltage limits, security limits and generation limits. The cold load pick up methodology has been employed to identify the most suitable location of DGs for enhancing the bus voltage profile [8]. The multi-objective particle swarm optimization (MPSO) technique has been formulated to discover the optimum size and location of DGs with minimization of two fitness functions such as economic and pollution costs of DG [9].

Past two decades, many power system optimization problems have been solved with the application of artificial intelligence (AI) algorithms [10-13]. Evolutionary programming method has been employed to identify the optimum location of TCSC and SVC in power system with cost function as active power loss minimization [10]. Some of the analysts have executed the use of AI methods to reduce the active power loss in RDS by installing DGs at appropriate buses [11-13]. The active power loss minimization has been considered as the fitness function to reconfiguration the large-scale RDS using improved tabu search algorithm (TSA) [11]. Ant colony search optimization (ACO) technique based radial network reconfiguration has been developed to minimize the system real power loss [12]. The optimum location and rating of DGs have been determined by utilizing both particle swarm optimization (PSO) and parameter improved PSO
(PIPSO) techniques with real power loss as swarm cost function and the minimization problem considers power balance constraint, DG generation limit and node voltage limit [13]. Besides, it has been proved that the optimum DG placement in RDS using PSO and PIPSO algorithms have better loss reduction and fast convergence properties [13]. PSO algorithm has pulled many investigators' sights due to its effectuality and simplicity. PSO algorithm animated from the bird flocking and fish schooling, is a flexible, robust, population based optimization technique that are implemented by many researchers to solve the engineering problems as well as various power system problems [14-16]. Numerous advantages and usefulness of the PSO algorithm can be seen in many research studies when solving the engineering optimization problems [14-20].

Unified Particle Swarm Optimization (UPSO) is an advanced method of PSO algorithm that harnesses the local and global variant of PSO, compounding their exploration and exploitation abilities without imposing additional requirements in terms of function evaluations. Preliminary studies have shown that UPSO can tackle efficiently different optimization problems $[21,22]$. The performance of UPSO has been firstly analysed on four different engineering constrained optimization problems with the fitness function similar to the power loss function of the electrical power distribution system. The framework which have been analysed with UPSO are design of a tension/compression spring, design of a welded beam, design of a gear train, and design of a pressure vessel [21].

Hence in this paper, UPSO is employed to find the desirable bus location and operating power of DGs in 33-bus and 69-bus power distribution systems. A real power loss minimization problem of distribution system is formulated using UPSO technique and the obtained results are compared to that of the GA, PSO and PIPSO algorithms, providing useful conclusions considering the effectiveness and proficiency of the proposed unified method.

After the introduction, a brief description of the DG placement problem colligated with its mathematical formulation is presented in Section 2, while in Section 3 explains the standard PSO and proposed UPSO algorithms. Simulation studies are presented in Section 4. Finally, the conclusion is drawn in Section 5. 


\section{Problem formulation}

It is manifested that the optimum power generation of DG at the desirable node can adequately decrease the active power loss of a radial distribution network [23]. Thus the objective of the presented work is gestated as active power loss minimization of distribution system, whose exact active power loss $P_{L}$ equation is represented as [24],

$\operatorname{Minimize} P_{L}=\sum_{i=1}^{n} \sum_{j=1}^{n}\left[\alpha_{i j}\left(P_{i} P_{j}+Q_{i} Q_{j}\right)+\beta_{i j}\left(Q_{i} P_{j}-P_{i} Q_{j}\right)\right]$

where,

$\alpha_{i j}=\frac{r_{i j}}{V_{i} V_{j}} \cos \left(\delta_{i}-\delta_{j}\right)$

$\beta_{i j}=\frac{r_{i j}}{V_{i} V_{j}} \sin \left(\delta_{i}-\delta_{j}\right)$

$Z_{i j}=r_{i j}+j x_{i j}$

where $r_{i j} \& x_{i j}$ is the resistance and reactance of the power line connecting nodes $i \& j$ respectively; $Z_{i j}$ is the impendence of the power line connectingnodes $i \& j ; V_{i} \& \delta_{i}$ is the bus voltage magnitude $\&$ angle at node $i$ respectively; $V_{j} \& \delta_{j}$ is the bus voltage magnitude $\&$ angle at node $j$ respectively; $P_{i}$ and $Q_{i}$ the real $\&$ reactive power injected at node $i$ respectively; $P_{j} \& Q=$ is the real and reactive power injected at node $j$ respectively; $n$ is the number of nodes in the system.

Subjected to constraints,

$>$ Real and reactive power balance

$P_{G i}-P_{D i}=\sum_{j=1}^{n} V_{i} V_{j}\left[G_{i j} \cos \left(\delta_{i}-\delta_{j}\right)+B_{i j} \sin \left(\delta_{i}-\delta_{j}\right)\right]$

$Q_{G i}-Q_{D i}=\sum_{j=1}^{n} V_{i} V_{j}\left[G_{i j} \sin \left(\delta_{i}-\delta_{j}\right)-B_{i j} \cos \left(\delta_{i}-\delta_{j}\right)\right]$

where $P_{G i} \& Q_{G i}$ is real \& reactive power generated by DG at node $i$ respectively; $P_{D i} \& Q_{D i}$ is real \& reactive power demand at node $i$ respectively; $G_{i j} \& \mathrm{~B}_{\mathrm{ij}}$ is the conductance \& susceptance of the power line connecting nodes $i \& j$ respectively.

DG power generation limits

$P_{G k \min } \leq P_{G k} \leq P_{G k \max }$

where $P_{\text {Gkmin }} \& P_{\text {Gkmax }}$ is minimum \& maximum power production limits of DG $k$ respectively.

Bus voltage limits

$$
V_{i \min } \leq V_{i} \leq V_{i \max }
$$

where $V_{\text {imin }} \& V_{\text {imax }}$ is minimum \& maximum voltage limits of bus $i$ respectively.

\section{Proposed methodology}

A new technique has been confronted in this section to discern the desirable bus location and operating power of DGs in RDS. This method expends the invention of naturally invigorated optimization algorithm called UPSO for real loss reduction in the radial power system by discovering the best appropriate bus location and operating power of DGs. In addition to UPSO technique, a backward-forward sweep power flow algorithm has been utilized to estimate the line flows and bus voltage of the radial power system coordinated with DGs [25]. The conception and algorithmic steps of the proposed UPSO for active power loss reduction in radial power distribution network equipped with optimal DGs is exemplified in the successive sections.

\subsection{Unified particle swarm optimization algorithm (UPSO)}

PSO technique is fundamentally admonished from the behavioral attributes of natural drift developed individual in bird flocking or fish schooling. In 1995, the thought of PSO technique to resolve the engineering problem was developed by Eberhart and Kennedy [14].

PSO technique investigates for global best solutions in an engineering optimization problem by working together with the particle in a population. Every individual in a population has prominent attributes of particle position and velocity. Theoretically, in an optimization problem, the particle's position ' $x$ ' and velocity ' $v$ ' is symbolized as working solution and step distance for successive iterations respectively.

For an optimization problem with ' $\mathrm{N}$ ' decision variables, let ' $m$ ' be the particle's population size, then the $i^{\text {th }}$ particle's position and velocity can be signified as $x_{i}=\left[x_{i l}, x_{i 2}, \ldots, x_{i N}\right]$ and $v_{i}=\left[v_{i l}, v_{i 2}, \ldots\right.$, $\left.v_{i N}\right]$ respectively. For every iteration, the position of $i^{\text {th }}$ particle is examined against its earlier optimal position. If the current position is better than the earlier optimum one, then it is officially appointed as the optimal local position for the corresponding particle, and it can be signified as $p_{i}=\left[p_{i l}, p_{i 2}, \ldots\right.$, $p_{i N}$. The overall optimal solution between all individuals in a swarm is perceived as the optimal 
global solution with position vector $p_{g}=\left[p_{g 1}, p_{g 2}, \ldots\right.$, $\left.p_{g N}\right]$. The $i^{\text {th }}$ particle's position and velocity for the successive iterations are modified by utilizing its present velocity and its step length between the optimal global position, and the optimal local position, the formula to amend the new position and velocity of the $i^{\text {th }}$ particle can be expressed as,

$v_{i d}^{t+1}=\omega . v_{i d}^{t}+\varphi_{1}\left(p_{g d}-x_{i d}^{t}\right)+\varphi_{2}\left(p_{i d}-x_{i d}^{t}\right)$

$x_{i d}^{t+1}=x_{i d}^{t}+v_{i d}^{t+1}$

where $\omega$ is inertia weight; $d$ is variable index; $\varphi_{1}=c_{1} r_{1} \& \varphi_{2}=c_{2} r_{2} ; c_{1} \& c_{2}$ are two positive acceleration coefficients called social and cognitive agents respectively; both $r_{1} \& r_{2}$ are uniform distribution random variables on the interval $[0,1]$; $t$ is the iteration count.

By stretching the scope and though of PSO technique, UPSO algorithm was first formulated by Parsopoulos and Vrahatis [21, 22], is a special version of PSO algorithm that controls the local and global parameters of PSO by compounding their discovery and development powers without enforcing extra duties when computing the fitness functions. This meliorated edition of UPSO technique can better both the local and global positions at the end of the iteration. Thus the proposed scheme requires less number of generation counts to achieve the globally best solution for any sort of optimization problems. The two parameters are employed in UPSO algorithm to achieve both the advantages of global and local particle's position updates. These two parameters can be expressed as follows,

$G_{i d}^{t+1}=\chi\left(v_{i d}^{t}+\varphi_{1}\left(p_{g d}-x_{i d}^{t}\right)+\varphi_{2}\left(p_{i d}-x_{i d}^{t}\right)\right)$

$L_{i d}^{t+1}=\chi\left(v_{i d}^{t}+\varphi_{1}^{\prime}\left(p_{h d}-x_{i d}^{t}\right)+\varphi_{2}^{\prime}\left(p_{i d}-x_{i d}^{t}\right)\right)$

where, $G^{t+1}{ }_{i d} \& L^{t+1}$ id represents the global and local parameter of particle's velocity update for particle i respectively; $\varphi^{\prime}{ }_{1}=c_{3} r_{3} \& \varphi^{\prime}{ }_{2}=c_{4} r_{4}$; where $c_{3}$ $\& c_{4}$ are two positive acceleration coefficients, $r_{3} \&$ $r_{4}$ both are uniform distribution random variables on the interval $[0,1] ; d$ is the dimension of the problem.

The two explore steps Eq. (11) and Eq. (12) are thus aggregated into a single form as,

$V_{i d}^{t+1}=r G_{i d}^{t+1}+(1-r) L_{i d}^{t+1}$ $x_{i d}^{t+1}=x_{i d}^{t}+V_{i d}^{t+1}$

where, $r$ is uniform distribution random variable on the interval $[0,1]$, which adverted to unification factor that identifies the shapes of both local and global explore steps. Evidently, $r=0$ and $r=1$ corresponds to local and global parameters of PSO algorithm. The aim of the presented paper is the desirable bus location and operating power of DG in RDS with the aid of UPSO. The implementation of the proposed method is described in the following section.

\subsection{Algorithmic procedure}

The algorithmic steps to discover the desirable bus location and operating power rating of DGs in RDS are discussed in this section.

Let ' $m$ ' be the population size and ' $N$ ' be the number of decision variables in an optimization problem. For optimal DG placement and sizing problem, the number of DGs to be installed in a radial system is ' $N / 2$ '; such that, a set of ' $N / 2$ ' variables to find optimal DG location and another set of ' $N / 2$ ' variables to calculate the optimal DG operating power.

Step 1: Read RDS's load and line data.

Step 2: Select suitable values for UPSO coefficients and set iteration index as $t=1$.

Step 3: Arbitrarily format workable solution for all ' $m$ ' particles in vector form $x_{i}=\left[x_{i 1}, x_{i 2}, x_{i N / 2}\right.$, $\left.x_{i N / 2+1}, \ldots, x_{i N}\right], i=1$ to $m$; where $x_{i 1}$ to $x_{i N / 2}$ represents DG location on the interval $[2, \mathrm{n}] ; x_{i N / 2+1}$ to $x_{i N}$ represents DG size on the interval $\left[P_{G k m i n}\right.$, $\left.P_{\text {Gkmax }}\right]$.

Step 4: For particle $i$, consider DG $\left(x_{i 2}\right)$ as negative load and locate at the bus $\left(x_{i 1}\right)$.

Step 5: For particle $i$, execute backward/forward sweep power flow algorithm on radial distribution with DG to estimate line flows, node voltage and active power loss using Eq. (1). Specify the estimated active power loss as fitness value to $i^{\text {th }}$ particle. Again go to step 4 for all remaining particles.

Step 6: Find the local optimum position $\mathrm{p}_{\mathrm{i}}$ for $i^{\text {th }}$ particle and the global optimum position $\mathrm{p}_{\mathrm{g}}$ among all particles on the basis of the minimal cost function.

Step 7: Modify UPSO global and local parameters using Eq. (11) and Eq. (12).

Step 8: Carry out particle's velocity and position update using Eq. (13) and Eq. (14) respectively.

Step 9: Verify the modified particle's position meets the system constraints Eq. (5) to Eq. (8); if 
any particles violate the limits, arbitrarily allocate the random solution to the violated position as in step 3; otherwise move to step 10.

Step 10: Whether the stopping conditions are met? i.e., is $t==t_{\max }$ ?; if yes, optimum rating and position of DG in a network, and the load flow solutions are obtained; if no, increment iteration count, and go to step 4.

The two different bench networks are examined, and the simulation outcomes are detailed in the following section to prove the skilfulness and capability of the presented work.

\section{Simulation results}

The presented methodology has been validated in two power distribution systems, and the simulation results are compared against the earlier existing methods such as GA, PSO, and PIPSO [13]. The first test network is 33-bus IEEE RDS with the active power demand of $3.72 \mathrm{MW}$ and reactive power demand of 2.3 MVAR [26]. The second test network is 69-bus IEEE distribution system with the active power demand of $3.8 \mathrm{MW}$ and reactive power demand of 2.69 MVAR [27].

Parameters utilized for simulation studies are,
- $\quad$ Population size, $m=10$

- Maximum iteration count, $t_{\max }=100$

- Inertia weight, $\omega$ is randomly selected between 0.9 and 0.4

- Social agent, $c l=2$ and $c 3=2$

- $\quad$ Cognitive agent, $c 3=2$ and $c 4=2$.

\subsection{3-bus distribution system}

The proposed method is simulated and demonstrated in 33-bus radial distribution network to find the optimal location and size of DG as per the algorithmic steps described in the previous section. The simulation outcomes obtained from the MATLAB environment is shown in Table 1. It is seen that the presented method shows the quality and merits over the early available methods in view point of active power loss minimization, voltage enhancement and simulation time. The bus voltage comparison graph between the radial distribution network with and without DG is depicted in Fig. 1. The convergence property of the proposed UPSO applied in 33-bus radial distribution network is presented in Fig. 2.

Table 1. Simulation result of 33-bus system

\begin{tabular}{|c|c|c|c|c|c|}
\hline \multicolumn{2}{|c|}{ Technique } & GA & PSO & PIPSO & UPSO \\
\hline \multicolumn{2}{|c|}{ Optimum location } & Bus 7 & Bus 7 & Bus 6 & Bus 6 \\
\hline \multicolumn{2}{|c|}{$\begin{array}{c}\text { Optimal size of DG } \\
(\mathrm{MW})\end{array}$} & 1.8832 & 2.2427 & 2.9312 & 2.5902 \\
\hline \multirow{2}{*}{$\begin{array}{c}\text { Active } \\
\text { power } \\
\text { loss } \\
(\mathbf{k W}) \\
\end{array}$} & $\begin{array}{c}\text { Without } \\
\text { DG }\end{array}$ & 210.9876 & 210.9876 & 210.9876 & 210.9876 \\
\hline & $\begin{array}{c}\text { With } \\
\text { DG }\end{array}$ & 117.0573 & 112.6898 & 112.6091 & 111.0188 \\
\hline \multicolumn{2}{|c|}{$\begin{array}{c}\% \text { Reduction in } \\
\text { active power loss }\end{array}$} & 44.5193 & 46.5893 & 46.6276 & 47.3813 \\
\hline \multirow{2}{*}{$\begin{array}{c}\text { Reactive } \\
\text { power } \\
\text { loss } \\
(\mathrm{kVAR})\end{array}$} & $\begin{array}{l}\text { Without } \\
\text { DG }\end{array}$ & 143.1284 & 143.1284 & 143.1284 & 143.1284 \\
\hline & $\begin{array}{c}\text { With } \\
\text { DG }\end{array}$ & 82.8449 & 82.6932 & 83.1180 & 81.7167 \\
\hline \multicolumn{2}{|c|}{$\begin{array}{c}\% \text { Reduction in } \\
\text { reactive power loss }\end{array}$} & 42.1184 & 42.2244 & 41.9276 & 42.9067 \\
\hline \multicolumn{2}{|c|}{$\begin{array}{c}\text { Computational } \\
\text { time (s) }\end{array}$} & 5.02 & 4.21 & 4.11 & 3.98 \\
\hline
\end{tabular}




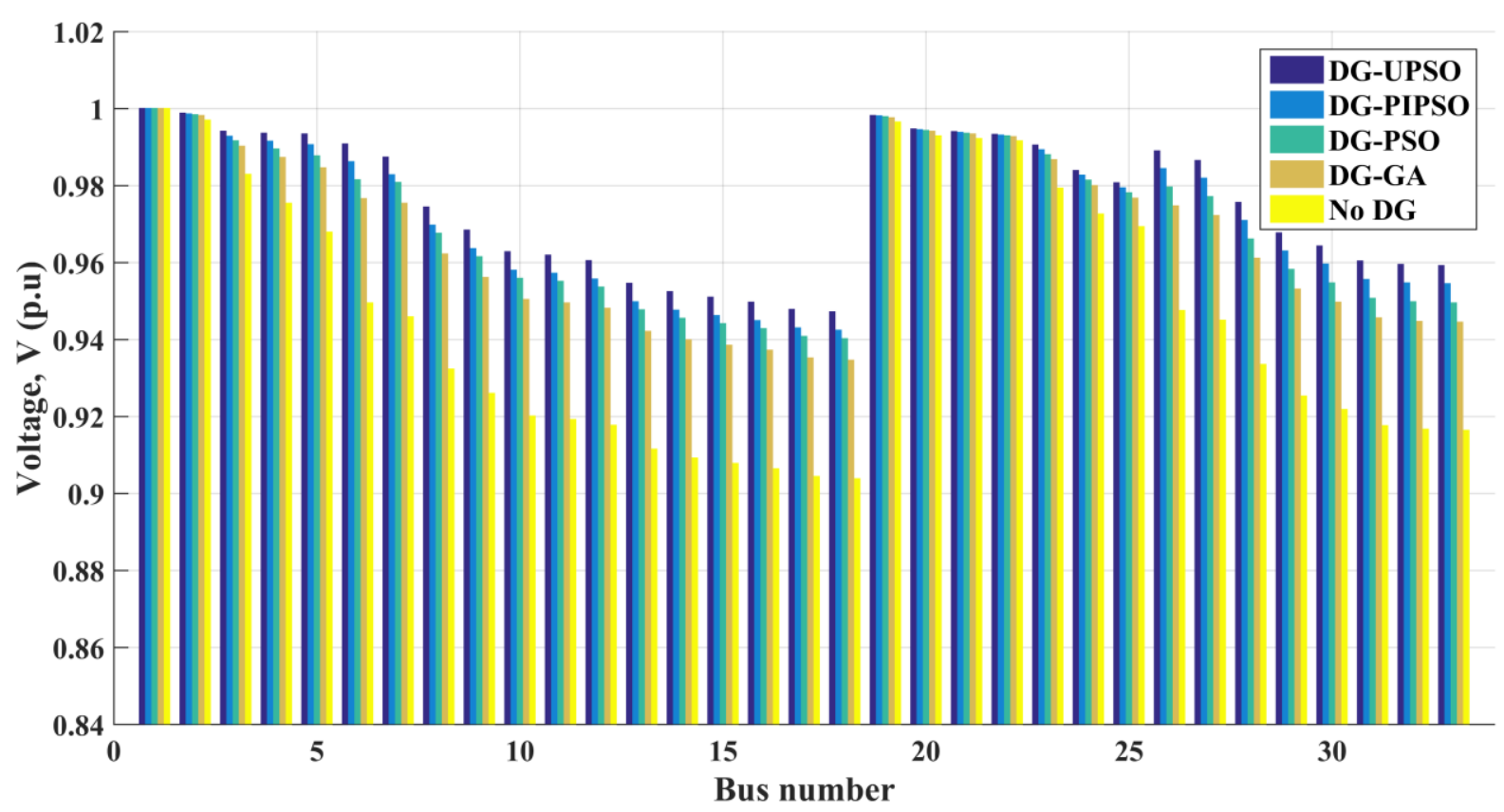

Figure.1 Comparison of bus voltage for 33-bus system

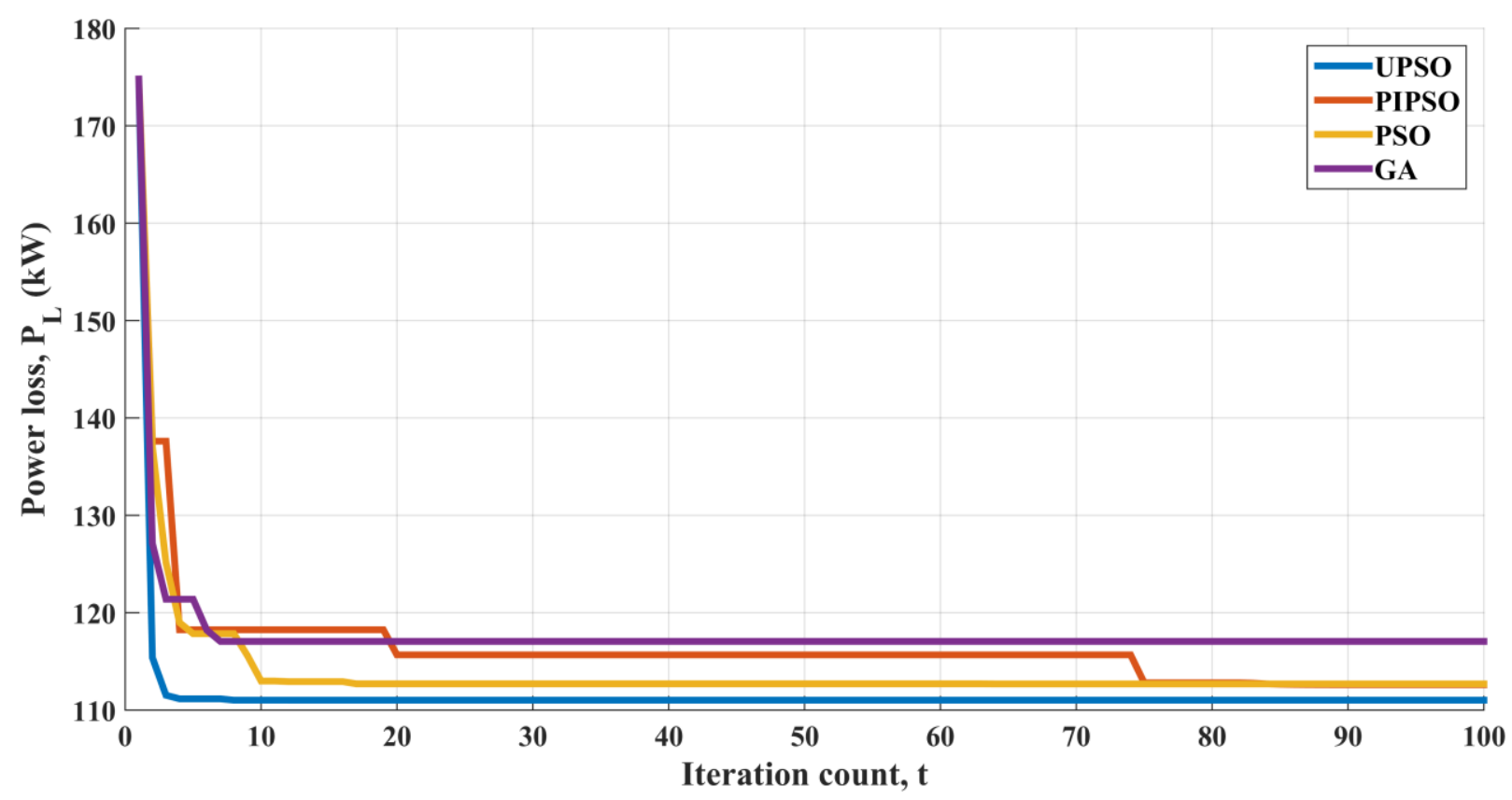

Figure.2 Convergence property for 33-bus system

\subsection{9-bus distribution system}

The UPSO algorithm is verified for power loss minimization in 69-bus radial distribution network by incorporating DG delivery active power in appropriate node. The simulation outcomes in Table 2 , shows the optimum position and size of DG and percentage of real power loss reduction in 69-bus radial distribution network. It is manifests that the presented method gives better results and takes less simulation time to identify the optimal DG when compared against the existing methods. Therefore, the use of the presented algorithm can also be extended to bigger power systems. The bus voltage comparison graph between the 69-bus radial distribution network with and without DG is shown in Fig. 3. The convergence property of the proposed UPSO employed in 69-bus radial distribution network is presented in Fig. 4. 


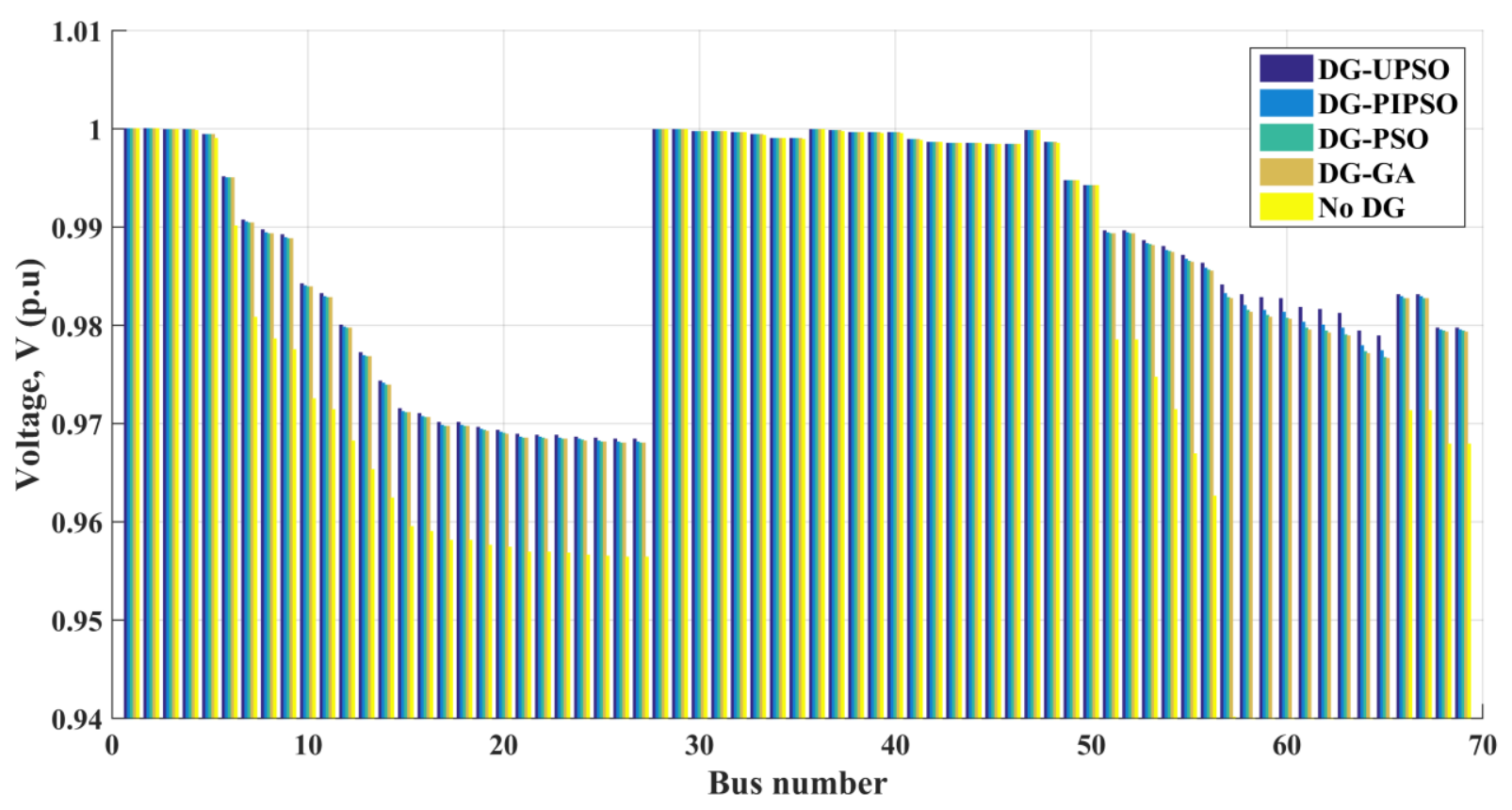

Figure.3 Comparison of bus voltage for 69-bus system

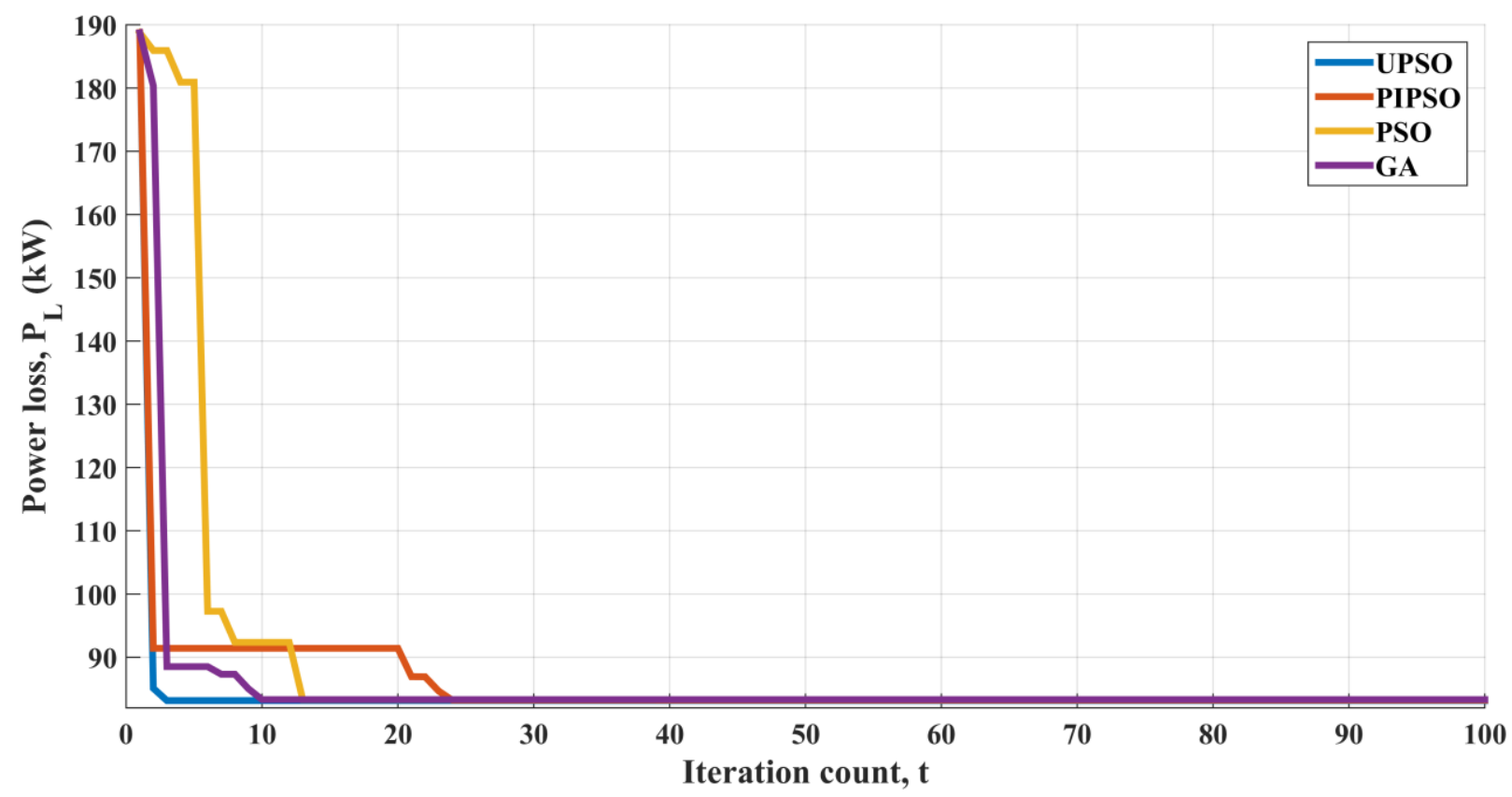

Figure.4 Convergence property for 69-bus system

Since, the presented edition of UPSO technique has improved local and global positions at the end of each generation. Thus the presented procedure takes very minimum number of iteration counts to obtain the optimal rating of DG in both 33-bus and 69-bus distribution systems. This can also clearly concluded from the table 1 and 2, the computational time taken to achieve the best solution of the presented UPSO method is much quicker than that of the existing algorithms such as GA, PSO and PISO. For both 33- bus and 69-bus test systems, the real power loss is also comparatively reduced in proposed UPSO technique when compared to existing methods. Similarly, the bus voltage profile of the system is also improved well in proposed UPSO method.

\section{Conclusion}

A method has been proposed to identify the optimum rating and location of DG in 33-bus and 
Table 2. Simulation result of 69-bus system

\begin{tabular}{|c|c|c|c|c|c|}
\hline \multicolumn{2}{|c|}{ Technique } & GA & PSO & PIPSO & UPSO \\
\hline \multicolumn{2}{|c|}{ Optimum location } & Bus 61 & Bus 61 & Bus 61 & Bus 61 \\
\hline \multicolumn{2}{|c|}{$\begin{array}{c}\text { Optimal size of DG } \\
(\mathrm{MW})\end{array}$} & 1.8046 & 1.8101 & 1.8285 & 1.8725 \\
\hline \multirow{2}{*}{$\begin{array}{c}\text { Active } \\
\text { power } \\
\text { loss } \\
(\mathbf{k W})\end{array}$} & $\begin{array}{c}\text { Without } \\
\text { DG }\end{array}$ & 224.8949 & 224.8949 & 224.8949 & 224.8949 \\
\hline & $\begin{array}{l}\text { With } \\
\text { DG }\end{array}$ & 83.3094 & 83.2842 & 83.2155 & 83.1476 \\
\hline \multicolumn{2}{|c|}{$\begin{array}{c}\% \text { Reduction in } \\
\text { active power loss }\end{array}$} & 62.9563 & 62.9675 & 62.9980 & 63.0282 \\
\hline \multirow{2}{*}{$\begin{array}{c}\text { Reactive } \\
\text { power } \\
\text { loss } \\
(\mathrm{kVAR})\end{array}$} & $\begin{array}{l}\text { Without } \\
\text { DG }\end{array}$ & 102.1155 & 102.1155 & 102.1155 & 102.1155 \\
\hline & $\begin{array}{l}\text { With } \\
\text { DG }\end{array}$ & 40.6690 & 40.6503 & 40.5941 & 40.4996 \\
\hline \multicolumn{2}{|c|}{$\begin{array}{l}\% \text { Reduction in } \\
\text { reactive power loss }\end{array}$} & 60.1735 & 60.1918 & 60.2469 & 60.3394 \\
\hline \multicolumn{2}{|c|}{$\begin{array}{c}\text { Computational } \\
\text { time (s) }\end{array}$} & 7.65 & 6.51 & 6.43 & 5.88 \\
\hline
\end{tabular}

69-bus IEEE radial power distribution systems with the aid of UPSO algorithm. The m-script has been coded and simulated in MATLAB environment. The outcomes obtained from the simulation studies manifest that the presented method has been superior in node voltage enhancement and active power loss minimization. It has been seen that the presented technique employing UPSO shows its master quality and benefits against the earlier existing algorithms such as GA, PSO, and PIPSO in the viewpoint of active power loss minimization, voltage enhancement and simulation time. Therefore in future work, the presented method can be extended to bigger power distribution network to find the optimum rating and position of DG. Similarly, the presented scheme can also be extended to multi DG placement for better loss reduction.

\section{References}

[1] A. Afsari, S.P. Singh, G.S. Raju, and G.K. Rao, "A fast power flow solution of radial distribution networks", International Journal Electric Components and Systems, Vol.30, No.10, pp.1065-1074, 2002.

[2] U.B. Tayab and M. Kashif, "A Modified Droop Controller for Parallel Operation of SinglePhase Inverters in Islanded Microgrid", International Journal of Intelligent Engineering and Systems, Vol.10, No.4, pp.11-17, 2017.

[3] S. Mayakrishnan, P. Srinivasan, and A. Loganathan, "Integrated Controller for
Elimination of Harmonics in PMSG Based WECS Feeding Non Linear Load", International Journal of Intelligent Engineering and Systems, Vol.10, No.3, pp.317-326, 2017.

[4] F. Abusief, R. Caldon, and R. Turri, "Implementation of distributed generation (DG) using solar energy resource to improve power system security in southern area in Libya", Power Engineering Conference (UPEC), 2014 49th International Universities, pp.1-6, 2014.

[5] M.M. Begovic, I. Kim, D. Novosel, J.R. Aguero, and A. Rohatgi, "Integration of photovoltaic distributed generation in the power distribution grid", In: System Science (HICSS), 2012 45th Hawaii International Conference on IEEE, pp.1977-1986, 2012.

[6] A. Silvestri, A. Berizzi, and S. Buonanno, "Distributed Generation Planning using Genetic Algorithms", In: Electric Power Engineering, 1999. PowerTech Budapest 99. International Conference on IEEE, pp.257, 1999.

[7] G. Celli and F. Pilo, "Optimal Distributed Generation Allocation in MV Distribution Networks", In: Power Industry Computer Applications, 2001. PICA 2001. Innovative Computing for Power-Electric Energy Meets the Market. 22nd IEEE Power Engineering Society International Conference on IEEE, pp.81-86, 2001.

[8] V. Kumar, I. Gupta, and H.O. Gupta, "DG integrated approach for service restoration under cold load pickup", IEEE Transactions on 
power delivery, Vol.25, No.1, pp.398-406, 2010.

[9] P. Phonrattanasak, "Optimal placement of DG using multiobjective particle swarm optimization", In: Mechanical and Electrical Technology (ICMET), 2010 2nd International Conference on IEEE, pp. 342-346, 2010.

[10] S.K. Kondakavali, B.R. Teegala, and A. Ksr, "Evolutionary Programming Approach for Deregulated Power Systems to Optimal Positioning of FACTS Devices", International Journal of Intelligent Engineering and Systems, Vol.10, No.2, pp.88-95, 2017.

[11] D. Zhang, Z. Fu, and L. Zhang, "An improved TS algorithm for loss-minimum reconfiguration in large-scale distribution systems", Electric Power Systems Research, Vol.77, No.5, pp.685-694, 2007.

[12] C.F. Chang, "Reconfiguration and capacitor placement for loss reduction of distribution systems by ant colony search algorithm", IEEE Transactions on Power Systems, Vol.23, No.4, pp.1747-1755, 2008.

[13] S. Angalaeswari and K. Jamuna, "Optimal placement and sizing of real power supporting DG in radial distribution networks", In: Electrical and Computer Engineering (WIECON-ECE), 2015 IEEE International WIE Conference on IEEE, pp.342-345, 2015.

[14] R.C. Eberhart and J. Kennedy, "A new optimizer using particle swarm theory" In: Sixth Symposium on Micro Machine and Human Science, Piscataway, IEEE Service Center, pp.39-43, 1995.

[15] H. Zhu, C. Pu, and J. Gu, "Improved Euclidean Particle Swarm and Application", International Journal of Intelligent Engineering and Systems, Vol.7, No.4, pp. 8-14, 2014.

[16] P. Vu, D. Le, N. Vo, and J. Tlusty, "A novel weight-improved particle swarm optimization algorithm for optimal power flow and economic load dispatch problems", In: Transmission and Distribution Conference and Exposition, IEEE PES, USA, pp.1-7, 2010.

[17] A. Rajamanickam and S.S. Mohideen, "A Multi-Wavelet Neural Network Particle Swarm Optimization Based MRPID of Interior Permanent Magnet Synchronous Motor Drives", International Journal of Intelligent Engineering and Systems, Vol.9, No.3, pp. 53-64, 2016.

[18] B. Kanisha and G. Balarishnanan, "Speech Recognition with Advanced Feature Extraction Methods Using Adaptive Particle Swarm Optimization", International Journal of
Intelligent Engineering and Systems, Vol.9, No.4, pp.21-30, 2016.

[19] R. Mendes, J. Kennedy, and J. Neves, "The fully informed particle swarm: simpler, maybe better", IEEE Transactions on Evolutionary Computation, Vol.8, No.3, pp.204-210. 2004.

[20] B.B. Savarala, and P.R. Chella, "An Improved Fruit Fly Optimization Algorithm for QoS Aware Cloud Service Composition", International Journal of Intelligent Engineering and Systems, Vol.10, No.5, pp.105-114, 2017.

[21] K.E. Parsopoulos and M.N. Vrahatis, "Unified Particle Swarm Optimization for Solving Constrained Engineering Optimization Problems", In: International Conference on Natural Computation, Springer, Berlin, Heidelberg, pp.582-591, 2005.

[22] K.E. Parsopoulos and M.N. Vrahatis, "UPSO: A unified particle swarm optimization scheme" Lecture Series on Computer and Computational Science, Vol.1, pp.868-873, 2004.

[23] N. Acharya, P. Mahat, and N. Mithulananthan, "An analytical approach for DG allocation in primary distribution network", International Journal of Electrical Power \& Energy Systems, Vol.28, No.10, pp.669-678, 2006.

[24] O.I. Elgerd, and H.H. Happ, "Electric Energy Systems Theory: An Introduction", IEEE Transactions on Systems, Man, and Cybernetics, Vol.2, No.2, pp.296-297, 1972.

[25] D. Shirmohammadi, H.W. Hong, A. Semlyen, and G.X. Luo, "A compensation-based power flow method for weakly meshed distribution and transmission networks", IEEE Transactions on Power Systems, Vol.3, No.2, pp.753 -762,1988.

[26] R.S. Rao, S.V.L. Narasimham, M.R. Raju, and A.S. Rao, "Optimal network reconfiguration of large-scale distribution system using harmony search algorithm," IEEE Transactions on Power Systems, Vol.26, No.3, pp.1080-1088, 2011.

[27] M.E. Baran and F.F. Wu. "Optimal capacitor placement on radial distribution systems", IEEE Transactions on Power Delivery, Vol.4, No.1, pp.725-734, 1989. 